\title{
ESTRATÉGIA DE LEITURA DE PREDIÇÃO NA ESCOLA: USO E CONSCIÊNCIA LINGUÍSTICA NO SEU USO
}

\author{
Vera Wannmacher Pereira* \\ Pontifícia Universidade Católica do Rio Grande do Sul \\ Escola de Humanidades - Letras \\ Porto Alegre, RS, Brasil
}

\section{Thais Vargas dos Santos \\ Colégio Monteiro Lobato \\ Porto Alegre, RS, Brasil}

\begin{abstract}
Resumo: Neste artigo é relatado estudo que examinou a contribuição, para alunos do $9^{\circ}$ ano do Ensino Fundamental, de materiais virtuais (informatizados) e não virtuais (impressos) com foco no uso da estratégia de leitura de predição e na consciência linguística de seu uso, utilizando o conto como texto. Teve como suporte teórico a Psicolinguística, especialmente em relação a esses dois tópicos centrais, e utilizou o apoio de tecnologias. Envolveu produção dos materiais e sua aplicação em oficinas na escola selecionada, elaboração e aplicação de testes antes e após as oficinas, assim como preparação continuada dos alunos bolsistas e professores. Os resultados indicaram diferença significativa na relação pré/pósteste no uso da predição e na consciência sobre seu uso; e na comparação entre as tecnologias, vantagem favorável à virtual, embora sem diferença estatística significativa. Como conclusão, cabe afirmar o alcance do objetivo e recomendar trabalho na escola com materiais com as propriedades estudadas.
\end{abstract}

Palavras-chave: Predição leitora. Uso e consciência linguística. Tecnologia. Conto literário.

\section{INTRODUÇÃO}

O reconhecimento de que a educação não vai bem, de que o ensino deixa a desejar, de que o aprendizado está longe de ser suficiente está presente em todos os segmentos sociais. Essa mesma percepção se aplica ao ensino e ao aprendizado da Língua Portuguesa. Professores expressam as dificuldades de leitura que observam em seus alunos, estes verbalizam seu próprio despreparo, familiares manifestam sua preocupação com o desinteresse dos filhos pelos estudos, empregadores apontam as dificuldades de absorção dos jovens estudantes pelo mercado. Acompanham essas percepções, fortalecendo-as, os dados obtidos por meio de instrumentos de avaliação oficiais nos diversos âmbitos.

\footnotetext{
* Pós-doutora em Psicolinguística. Professora do Programa de Pós-graduação em Letras. E-mail: vpereira@pucrs.br

** Doutora em Letras. E-mail: thais.vsantos@ hotmail.com
} 
Esse conjunto de percepções e dados gera análises e reflexões em busca de variáveis que possam estar a influenciar esse quadro. Entre as variáveis que podem contribuir para isso, está a questionável produtividade das aulas tanto da parte da eficiência da ação docente quanto do aproveitamento discente, podendo esse fato estar associado ao recorte teórico-metodológico utilizado, possivelmente distanciado das convicções linguísticopedagógicas atuais e das características do público estudantil que hoje ocupa os bancos escolares, especialmente os públicos.

Nesse entendimento, foi desenvolvido ${ }^{1}$ um projeto de estudos psicolinguísticos aplicados, com suporte da Computação, associando ensino, extensão e pesquisa, que teve como foco o uso de estratégia de leitura e a consciência linguística do leitor desse uso. Para tanto, elegeu o conto como texto de leitura, cujas propriedades estão de acordo com o público previsto, considerando seus interesses e possibilidades e as vivências escolares. Assim definido, teve, como objetivo, examinar a contribuição de materiais linguísticopedagógicos virtuais e não virtuais com foco na estratégia de predição leitora (uso e consciência), sendo o conto o texto de leitura, para alunos do $9^{\circ}$ ano do Ensino Fundamental, ano escolar estratégico na medida em que, além de evidenciar dificuldades de leitura, conforme as provas oficiais, fecha o processo desse nível de ensino e estabelece vínculos com o nível seguinte.

Para tanto, foram produzidos materiais virtuais e não virtuais de ensino com essas características, preparados continuadamente por professores e bolsistas IC e IC Júnior, planejadas e realizadas oficinas utilizando esses materiais, elaborados e aplicados instrumentos de pesquisa e examinados os dados obtidos. Os processos e produtos pedagógicos desse trabalho, apresentados neste artigo, estão divulgados por meio de um e-book disponível no site da EDIPUCRS ${ }^{2}$.

Neste artigo, são expostos sucessivamente o contexto de aprendizado e ensino da leitura e o estudo realizado, em seus fundamentos, no delineamento adotado e nos resultados alcançados, de modo a esclarecer os processos desenvolvidos e seus produtos e evidenciar a contribuição de iniciativas com essas propriedades em situações escolares que revelam dificuldades de compreensão leitora por estudantes do final do Ensino Fundamental.

\section{CONTEXTO DE APRENDIZADO E ENSINO DA LEITURA}

Dados decorrentes de avaliações oficiais vêm evidenciando as condições não satisfatórias dos estudantes do Ensino Fundamental no que se refere ao manejo de materiais de leitura. Entre essas provas está a do $\mathrm{PISA}^{3}$ da $\mathrm{OCDE}^{4}$, que consiste num programa internacional de pesquisa trienal de competências de estudantes na faixa dos 15 anos de idade, cujos dados são especialmente importantes para o estudo aqui relatado.

\footnotetext{
${ }^{1}$ Com apoio do Conselho Nacional de Desenvolvimento Científico e Tecnológico - CNPq, da Coordenação de Aperfeiçoamento de Pessoal de Ensino Superior - CAPES e da Fundação de Amparo à Pesquisa do Rio Grande do Sul - FAPERGS.

$2<$ http://ebooks.pucrs.br/edipucrs/projetos/100815-001/>

${ }^{3}$ Programa de Avaliação Internacional de Estudantes.

${ }^{4}$ Organização para a Cooperação e Desenvolvimento Econômico.
}

PEREIRA, Vera Wannmacher; SANTOS, Thais Vargas dos. Estratégia de leitura de predição na escola: uso e consciência linguística no seu uso. Linguagem em (Dis)curso - LemD, Tubarão, SC, v. 17, n. 3, p. 361-380, set./dez. 2017. 
No ano de 2000, o Brasil obteve 396 pontos em leitura, ocupando a última posição no ranking entre 32 países participantes da edição de avaliação. Em 2003, o Brasil melhorou o desempenho em relação à edição anterior, atingindo 403 pontos, entre 41 países. No PISA de 2006, em que 56 países realizaram a avaliação, o Brasil regrediu, atingindo 393 pontos e ficando com a 49 posição no ranking. No ano de 2009, o Brasil ficou no $53^{\circ}$ lugar, entre 65 países, com 412 pontos. Na avaliação realizada em 2012, o Brasil não melhorou o seu desempenho em leitura, ficando com pontuação inferior à registrada na edição de 2009 - 410 pontos e $55^{a}$ posição. Em 2015, entre 70 países, o Brasil ficou na $59^{\mathrm{a}}$ posição. Nesse ano, $50,99 \%$ dos estudantes brasileiros ficaram abaixo do nível 2 de proficiência, com média de desempenho de 407 pontos. Em perspectiva evolutiva, o Brasil, no que se refere à leitura, apresentou os seguintes dados: 396 (2000), 403 (2003), 393 (2006), 412 (2009), 410 (2012) e 407 (2015), indicando índices muito baixos e predominantemente em decrescimento.

Conforme esses dados, são grandes as dificuldades dos estudantes brasileiros dessa faixa etária, na leitura de textos, colocando o Brasil numa posição desfavorável no ranking dos países participantes. Para entendimento da situação, é importante examinar um pouco do contexto em alguns de seus pontos evolutivos, o que pode de algum modo explicar as preocupações dos diversos segmentos sociais brasileiros.

Até o final dos anos 60, a leitura ocupava um lugar privilegiado no trabalho escolar. Todos os conteúdos eram aprendidos por meio da leitura continuada e sistemática de materiais escritos impressos - livros didáticos, enciclopédias, dicionários, manuais, almanaques - assim como a cultura era vivida por meio das obras literárias. No $1^{\circ}$ ano, a alfabetização tinha como cerne a leitura - da cartilha e da ficção literária. Nos anos seguintes do então curso primário, os "pontos" das diversas áreas do conhecimento, escritos no quadro de giz pelo professor, eram copiados nos cadernos, lidos e examinados miudamente por meio de questionários longos e densos. A biblioteca era centro das atenções - para realização de consultas, retirada de livros e vivência de hora específica de leitura - momento em que os alunos eram orientados na escolha e tinham oportunidade de ouvir histórias da professora que ali trabalhava. Na escola, então, havia muito a ler.

Nos anos finais do então Curso Ginasial (hoje Ensino Fundamental), a leitura ampliava ainda mais seu espaço por meio das obras ficcionais extensas e dos livros didáticos com textos informativos consistentes, de autores de reconhecido valor. O livro didático de Língua Portuguesa trazia coletânea de textos literários clássicos, de qualidade indubitável. Esse trabalho era intensificado pelo ensino do Latim, do Francês e do Inglês, que se caracterizava por atividades de tradução e versão. Desse modo, os estudos da língua materna e das línguas estrangeiras auxiliavam-se mutuamente. Os estudos gramaticais nessa faixa, paralelos ao trabalho de leitura, eram de grande complexidade, esquadrinhando a estrutura da Língua Portuguesa.

Esse caminho foi interrompido pela Lei 5692/71. A formação acadêmica e humanística a longo prazo cedeu espaço à então chamada Iniciação à Técnica a curto prazo. A Língua Portuguesa passou a ser Língua Nacional, integrando a Área de Comunicação e Expressão, em condições equivalentes à Educação Física e à Educação Artística. A partir desse momento, que se caracterizou pela invasão da imagem, da cor e do movimento e, com eles, das mídias, o livro e, com ele, a leitura, perderam espaço na 
vida cotidiana e no ensino escolar. A comunicação se tornou a palavra de ordem, trazendo consigo a exploração dos elementos que a constituem e das diversas semióticas. Os estudos gramaticais ficaram perdidos em meio a tudo que acontecia, espalhando-se o entendimento de que não eram mais convenientes, embora ainda permanecessem alguns tópicos de gramática normativa sem associação significativa com a exploração de textos.

Nos anos 1980, estudos teóricos próprios da Educação deram maior nitidez ao processo de aprendizado pelo aluno e, como decorrência, apontaram a necessidade de identificação de caminhos de ensino mais produtivos, buscando, para isso, conexões com diferentes áreas. Um novo paradigma se instalou, sendo as novas propostas curriculares desenvolvidas a partir dele. A Computação ocupou um importante espaço que se abriu, trazendo contribuições para o ensino. Entretanto, sua complexidade e a necessidade de programador preparado obstaculizaram seu uso no ensino. Aos poucos, a ideia de interface, gradativamente construída, colaborou para ações integradas permitindo, então, a geração de atividades pedagógicas. No caso do ensino da leitura, as iniciativas surgiram e se desenvolveram, com benefícios para os aprendizes. A Linguística, por sua vez, no que se refere aos estudos sobre textos e sobre estrutura e funcionamento da linguagem, contribuiu para a ampliação do espectro dos materiais de leitura e para nova dimensão do conceito de leitura e suas relações com a gramática. No entanto, as dificuldades de transposição dos estudos linguísticos para o ensino mantiveram a gramática normativa no cotidiano escolar, acompanhada de algumas tentativas dos estudos linguísticos do texto. A leitura, como acesso à arte e ao prazer, passou a dar lugar à leitura como compreensão e processamento. As descobertas desse período foram estabelecendo algumas de suas bases, que estão apoiando os direcionamentos da atualidade - às vezes auxiliando, às vezes confundindo os professores.

Na sucessão desses fatos e perspectivas, nos anos finais do Ensino Fundamental e no Ensino Médio, vem ocorrendo hoje uma tentativa de aproveitamento dos conhecimentos produzidos pelos estudos do texto e do discurso - o uso de gêneros textuais diversos e a organização de atividades explorando coerência, coesão e aspectos contextuais. Essas atividades são propostas com objetivo pouco claro, não sabendo o professor onde situá-las - se na leitura, se na gramática. Isso se deve ao fato de que entende como atividades de leitura os questionamentos sobre o conteúdo do texto e como atividades de gramática as classificatórias baseadas nos estudos normativos. Nessa configuração, há uma dissociação entre o ensino da leitura e o da gramática, assim como em relação ao ensino da escrita, conforme pode ser constatado na indicação de um determinado gênero para ler e de um outro gênero para escrever.

Desse modo, o ensino de leitura atualmente, embora haja alguns avanços, continua com espaço reduzido na escola, alheio ao percurso histórico e dissociado dos estudos linguísticos, especialmente dos psicolinguísticos, gerando pouca produtividade, como mostram os dados avaliativos já apresentados. Essa situação certamente não está vinculada a um simples querer do professor, mas à persistente escassez de pesquisas que examinem a contribuição de uns e outros paradigmas linguísticos e da efetiva contribuição da interface, especialmente com a Computação, para o seu aprendizado, reconhecendo tudo isso como condição.

Com a convicção da urgente necessidade de aplicação teórica da Psicolinguística e de busca de caminhos nas tecnologias, foi desenvolvido o estudo aqui relatado, estando exposto a seguir em seus fundamentos, seu delineamento metodológico e seus resultados. 
O estudo aqui relatado é sustentado teoricamente na perspectiva de leitura como processo psicolinguístico voltado para o texto.

Nesse entendimento, a leitura ocorre por meio de dois processos básicos (SCLIARCABRAL, 2008, 2009) que interagem conforme a situação de leitura - o bottom-up e o top-down. O processo bottom-up caracteriza-se como ascendente, fazendo o movimento das partes para o todo. Constitui-se numa leitura linear, minuciosa, vagarosa, em que todas as pistas visuais são utilizadas. É um processo de composição, uma vez que as partes gradativamente vão formando o todo. O processo top-down, defendido especialmente por Goodman (1991) e por Smith (2003), caracteriza-se como um movimento não linear que faz uso de informações não visuais, dirigindo-se do mais geral para o mais específico, do todo para as partes, da macroestrutura para a microestrutura. O modelo de Goodman baseia-se na concepção antecipatória da leitura, segundo o qual as informações linguísticas têm um duplo papel: levantar e testar hipóteses.

Considera-se que os dois movimentos são utilizados pelo leitor, dependendo da situação que se apresenta durante a leitura, envolvendo o próprio texto, o objetivo da leitura e o leitor (conhecimentos prévios). Nesse sentido, o sucesso do desempenho na compreensão da leitura está na escolha do processo mais eficiente para dar conta da situação de leitura, em que variáveis se inter-relacionam e produzem influências.

Esses processos ocorrem por meio de dois grupos básicos de estratégias: cognitivas e metacognitivas (KATO, 1987; KLEIMAN, 1989; LEFFA, 1996). As estratégias cognitivas caracterizam-se pelos traços intuitivo e inconsciente, enquanto as metacognitivas caracterizam-se pela consciência, pela intenção de monitoramento do próprio processo. Constituem-se em exemplos de estratégias cognitivas pressuposições intuitivas do leitor, tais como a de que o texto é, a priori, coerente, a de que determinadas ordenações são impossíveis e a de que a escrita, em nossa cultura, ocorre da esquerda para a direita. Constituem-se em exemplos de estratégias metacognitivas situações de monitoramento e autorregulação do processo pelo leitor com o objetivo de garantir a compreensão, tais como: a definição e o controle do objetivo da leitura, a identificação de segmentos importantes, a distribuição da atenção, a avaliação da qualidade da compreensão e a tomada de medidas corretivas. O exame dessas estratégias expõe os elementos que internamente as constituem e que estão distribuídos nos planos constitutivos da língua - fônico, mórfico, sintático, semântico, pragmático e textual (GOMBERT, 1992).

Os estudos psicolinguísticos sobre o assunto indicam a existência de um conjunto de estratégias acionadas durante a leitura. Entre essas, são nomeadas com muita frequência: skimming, scanning, predição, automonitoramento, autoavaliação, autocorreção, inferência e leitura detalhada (KATO, 1987; KLEIMAN, 1989; LEFFA, 1986; GOODMAN, 1991; SMITH, 2003). De modo a dar continuidade a trabalhos anteriores, foi eleita, para o estudo aqui relatado, como estratégia de leitura para produção, aplicação e investigação das atividades pedagógicas, a de predição.

O significado da estratégia de predição está no próprio radical da palavra, permitindo associação a predizer. Possibilita vincular também significativamente a previsão, a antecipação e até mesmo a adivinhação.Em relação a esta última, há que explicitar que não se trata de um procedimento impulsivo e aleatório. Consiste num 
procedimento em que o leitor, com base nas pistas linguísticas e nos seus conhecimentos prévios, faz importantes inferências. Daí a denominação guessing game, de Goodman (1967).

A seleção das pistas está apoiada no objetivo do leitor, isto é, do que ele deseja antecipar, nas características do texto, isto é, na natureza dos elementos linguísticos que o autor disponibiliza, e nos conhecimentos prévios de que o leitor dispõe para sua busca. Cabe ressaltar que num poema, por exemplo, a predição de uma palavra pode estar apoiada em uma rima anterior, assim como na morfologia de uma palavra ou na estrutura de um verso. Do mesmo modo, a predição de um fato pode estar vinculada à sequência de fatos antecedentes, assim como a predição de uma palavra pode estar no campo semântico do qual faz parte.

A estratégia de predição tem em si um processo com apoio em outras estratégias de grande importância para o seu êxito - o automonitoramento, a autoavaliação e a autocorreção (PEREIRA; PICCINI, 2006). Constituem-se esses componentes como condições para uma predição eficiente, cabendo ao leitor estar consciente de sua importância e da necessária interação entre elas.

Considerando esse conjunto de concepções, cabe assumir o ponto de vista de que o processo cognitivo de compreensão da leitura (PEREIRA, 2008) se realiza em rede, com os necessários ajustamentos, do que decorre sua natureza de jogo e consequentemente de risco, que exige da parte do leitor o manejo de processos ascendentes e descendentes e de estratégias cognitivas e metacognitivas de leitura (KLEIMAN, 1989). Nessa dimensão, a compreensão da leitura conta com a consciência do leitor sobre a linguagem, tópico desenvolvido na sequência.

As concepções sobre consciência desenvolvidas por Baars (1993), Bächler (2006) e Dehaene (2009) constituem importantes referências.

A teoria do espaço global da consciência (global workspace) foi desenvolvida por Baars, segundo a qual os conteúdos conscientes estão contidos num espaço global: uma espécie de processador central usado para mediar a comunicação com um conjunto de processadores especializados não conscientes. Quando esses processadores especializados precisam transmitir informação para o resto do sistema, eles o fazem mandando informação para o espaço global que atua como uma espécie de quadro comunitário, acessível a todos os outros processadores.

Bächler (2006) apresenta as propriedades da consciência: tem um foco circundado por informações que proporcionam um contexto, é dinâmica, tem um ponto de vista, necessita de uma orientação. Consistindo em traço central da mente, ela é indispensável para compreender qualquer processo cognitivo, sendo que sua estrutura intencional a vincula ao mundo. No caso da consciência sobre a linguagem, é fundamental a significação das palavras, das frases e dos textos.

Dehaene (2009) relata que, em seus experimentos, evidencia-se que, a partir do tempo de 270-300 milissegundos, é possível ver diferença entre o processamento consciente e o inconsciente. Isso ocorre a partir do momento em que diferentes áreas do cérebro entram em sincronia. Desse modo, a consciência não é realizada por uma área do cérebro, mas pela sincronia entre muitas regiões, a partir de um tempo de trabalho, conforme indicado acima. 
Essas concepções sobre consciência (DEHAENE, 2001, 2007) são importantes para tratar especificamente da consciência linguística. Pode ser, então, explicitada como apresentando as seguintes propriedades: ativa em sincronia diversas áreas do cérebro; tem um foco linguístico específico; utiliza informações periféricas a esse foco - o contexto; é intencional na busca da análise de algum ponto específico.

A consciência linguística (SPINILLO; MOTA; CORREA, 2010), que aqui interessa por seu vínculo com a compreensão leitora, volta-se para o conhecimento da própria linguagem em todos os modos de constituição e organização, estando predominantemente associada à memória declarativa e direcionada para o manejo desses elementos linguísticos.

Nesse entendimento, a consciência linguística (GOMBERT, 1992) pode focalizar determinado segmento linguístico, considerando sempre o contexto dos demais segmentos (MOTA, 2009). Essa condição faz com que ela seja categorizada de acordo com cada um desses segmentos em atenção. A consciência fonológica tem como foco os fonemas (consciência fonêmica) e as sílabas (consciência silábica) que constituem a estrutura linguística e as propriedades entonacionais e rítmicas da língua em uso. A consciência morfológica tem como ponto de observação o vocábulo - os limites de início e fim, a estrutura (constituintes lexicais e gramaticais), os processos flexionais (gênero, número, pessoa/número, tempo/modo) e os processos derivacionais. A consciência sintática (RIGATTI; PEREIRA, 2015) direciona seu olhar para a frase internamente: seu limite (início e final da frase), seus constituintes (e suas relações). A consciência léxicosemântica abrange o léxico mental (vinculado à memória lexical), o significado (significação básica) e o sentido (construção $a d$ hoc). A consciência pragmática volta-se para a situação de uso da língua, considerando enunciador/receptor, objetivo, suporte comunicativo, momento e espaço da comunicação. A consciência textual se direciona para as marcas linguísticas que constituem o material escrito como texto.

Conforme Gombert (1992), a consciência textual, importante no estudo aqui relatado devido a constituir-se em leito para os demais níveis de consciência, focaliza a superestrutura, a coerência e a coesão do texto. A superestrutura envolve os traços que definem o texto como um determinado gênero (BAZERMAN, 2009), contribuindo para isso a situação comunicativa (autor, leitor, tempo, espaço, suporte) e o modo de organização - moldura, componentes constitutivos (unidades linguísticas), sequências dominantes - narrativa, descritiva, argumentativa, injuntiva, expositiva (ADAM, 2008), traços linguístico-estruturais (próprios dos diversos planos linguísticos). A coerência se refere predominantemente ao conteúdo e suas relações internas e com o entorno, que podem ser explicitadas nas regras definidas por Charolles (1978), como manutenção do tema, progressão do tema, ausência de contradição interna e relação com o mundo. A coesão (HALLIDAY; HASAN, 1976) consiste nos liames linguísticos do texto que contribuem para sua amarração e, assim, para a construção de seus sentidos. Apresentase em duas dimensões - a coesão lexical (palavras lexicais) e a coesão gramatical (palavras gramaticais).

Esse conjunto de fundamentos integra o processamento da leitura, cabendo considerá-los como base tanto para o suporte virtual como para o não virtual, especialmente quando se deseja ver as aproximações e os afastamentos, como é o caso do estudo aqui relatado. A opção por esse caminho está apresentada na continuidade deste texto. 
Com frequência há, na família, na escola, na sociedade em geral, a convicção de que o computador é um dos grandes obstáculos para que as crianças e os jovens gostem de ler. Os estudos que vêm sendo desenvolvidos (PEREIRA; ANTUNES, 2003; PEREIRA, 2006, 2009, 2010) não confirmam esse entendimento. Salienta-se, primeiramente, a esse respeito, que as pesquisas sobre redes cognitivas permitem o estabelecimento de convergências importantes entre o processo cognitivo de leitura e o sistema que constitui o computador, ambos em rede. Disso decorre principalmente a adequação desse equipamento como caminho para a pedagogia da leitura. Além disso, a dimensão interativa que ele possibilita, movida pela ação desenvolvida pelo aluno e pelo professor/monitor, pode tornar o trabalho pedagógico mais produtivo, na medida em que mantém esses usuários interessados no trabalho que é proposto. Revela-se, como decorrência, que, utilizando-o como ferramenta, o grau de satisfação pode ser elevado, a autoestima ser acentuada, podendo favorecer o aprendizado.

Essas constatações estão provavelmente vinculadas ao processo de interação que se estabelece entre o usuário e a máquina e às associações possíveis entre as redes cognitivas daquele e as redes eletrônicas desta (PEREIRA, 2006).Alguns estudos sobre leitura na tela discutem seus possíveis efeitos em novos modos de ler e escrever (TONNESSEN, 2006), donde a importância de examinar esses processos. Diante disso, não pode ser negada a existência de um equipamento atraente e que traz em si a possibilidade de constituir-se em elemento instigador do desejo de ler e, o mais importante, orientador do processo de ler (MILLER, 2009; COSCARELLI, 2002).

Outros estudos mostram as semelhanças e as diferenças entre a leitura em papel e a leitura em tela, bem como suas implicações na formação de um leitor com determinadas características (PEREIRA, 2016).

Do mesmo modo, a folha de papel, que recebe um texto impresso, consiste numa tecnologia não virtual, que por bastante tempo foi única. Hoje, em meio ao virtual, ela continua com seu lugar garantido. A escola, por razões culturais e de infraestrutura, lhe dá um espaço privilegiado. As pesquisas sobre compreensão leitora têm sido predominantes no suporte impresso, do que decorre a existência de maior número de dados nesse formato.

Conforme Pereira (2016), a leitura em papel exige do leitor procedimentos importantes e que têm semelhanças com a leitura virtual, como o uso de estratégias e processos e a realização de conexões com os conhecimentos prévios. Há também diferenças, como a linearidade mais presente na leitura em papel. Segundo a autora, no entanto, há que reconhecer a exigência da leitura virtual para comportamentos de autonomia, fortalecendo o leitor como agente, considerando as características de multimodalidade, interconectividade e interatividade. Daí decorre a importância de examinar os dois modos tecnológicos.

\section{DELINEAMENTO METODOLÓGICO DO ESTUDO}

No estudo aqui exposto, os dois tipos de tecnologia estão presentes na elaboração, aplicação e investigação de atividades pedagógicas com foco em uso de estratégia de leitura e consciência nesse uso, na medida em que cabe examinar sua produtividade em 
seu manejo na leitura de contos literários (BAZERMAN, 2009; ADAM, 2008), por estudantes de $9^{\circ}$ ano do EF.

Nessa perspectiva, o estudo teve como objetivo central verificar a contribuição de oficinas (20 horas) com materiais em tecnologias virtuais e não virtuais com foco na estratégia de leitura de predição do conto, para o uso dessa estratégia e a consciência linguística em seu uso por alunos do $9^{\circ}$ ano do EF.

Considerando esse objetivo, nortearam o trabalho as seguintes questões de pesquisa: a) qual a diferença pré e pós-teste de oficinas com materiais virtuais e não virtuais com foco na estratégia de leitura de predição, em contos, para o uso dessa estratégia e a consciência linguística nesse uso?; b) em que medida o uso e a consciência no uso da estratégia de leitura de predição trabalhada estão associados às tecnologias utilizadas (virtual e não virtual)?

A escolha do conto como gênero textual a ser trabalhado decorreu dos resultados de estudos anteriores que o apontaram como apresentando dificuldades de compreensão aos estudantes sujeitos (AMODEO; PEREIRA, 2016), da observação da sua baixa frequência nos espaços escolares e das conversas com os professores das turmas que o indicaram como oportuno para avanço dos alunos, considerando os programas de ensino da escola, a faixa etária e o nível de escolaridade desses meninos e meninas. A seleção dos contos para as atividades de ensino e para as de pesquisa teve como critério predominante a adequação linguística e temática aos estudantes, diante de suas possibilidades e interesses, tendo sido esse processo realizado pela equipe, mediante cuidadoso trabalho de análise e reflexão.

As nove atividades de ensino foram reunidas em três módulos, gerados em tecnologia virtual e em tecnologia não virtual, tendo sido cada atividade constituída de uma tarefa de uso da estratégia de leitura de predição (UELP) e de uma tarefa de consciência no uso dessa estratégia (CUELP). Essas atividades, focalizando a predição leitora, foram orientadas, no que se refere aos conteúdos, pelos segmentos linguísticos apontados por Gombert (1992) como componentes da consciência linguística, com predomínio dos que constituem a consciência textual, assim como pelas definições de Adam (2008) sobre os componentes textuais. Desse modo, o conto consiste no material de leitura (virtual e não virtual) escolhido para estudo do uso da predição e da consciência sobre seu uso, voltados para esses componentes em abordagem psicolinguística.

Para a construção do material, foram selecionados três contos distribuídos em três módulos: A - "A noite em que os hotéis estavam cheios", de Moacyr Scliar; B - "Um Apólogo", de Machado de Assis; C - "Betsy", de Rubem Fonseca. Esses módulos contemplam um conjunto de atividades voltadas para o desenvolvimento da estratégia de predição - uso e consciência no seu uso. Essas atividades, seis em cada módulo, contemplam textos que são apresentados aos poucos de modo que o aluno, com apoio nas pistas linguísticas do trecho apresentado, faça predições sobre aspectos linguísticos do texto como, por exemplo, o agrupamento de palavras que pode aparecer no texto, o gênero a que o texto pertence, palavras que faltam no texto, sinais de pontuação que não estão incluídos. Para cada questão de uso da estratégia, o aluno deve justificar sua escolha, estabelecendo, assim, a consciência no uso da estratégia de predição. Os materiais elaborados mantêm correspondência entre o ambiente virtual e o ambiente não virtual, de modo a garantir a equivalência dos processos desenvolvidos. As diferenças se restringem às adaptações necessárias ao suporte - material impresso e tela do computador. 
Para o desenvolvimento da pesquisa, foram realizadas dez oficinas de duas horas cada uma (totalizando 20 horas), as quais ocorreram em dois ambientes da escola participante: as atividades com uso de tecnologia não virtual nas salas de aula das respectivas turmas; e as atividades de tecnologia virtual na sala de informática da escola, que é equipada com netbooks, equipamentos adquiridos com recursos da escola e utilizados para a realização das atividades virtuais.

Essas oficinas foram conduzidas por duas professoras da escola participante do projeto (Bolsistas AT), dois graduandos de Letras (bolsistas IC), uma doutoranda em Letras (bolsista integral do CNPq), um estagiário da Computação e seis estudantes da escola (bolsistas IC Júnior). Aos professores e aos acadêmicos IC cabia orientar a realização das atividades. À doutoranda cabia o acompanhamento da pesquisa, desde a elaboração dos materiais até a realização do relatório final. Ao estagiário da Computação cabia o controle do funcionamento dos equipamentos. Aos alunos IC Júnior competia auxiliar os colegas no desenvolvimento das atividades. A participação de dois professores de Língua Portuguesa da escola e de seis alunos do Ensino Fundamental na condição de bolsistas de Apoio Técnico e de bolsistas de Iniciação Científica Júnior, respectivamente, decorreu da aprovação do projeto em edital especial da FAPERGS/CAPES, designado para o desenvolvimento de projetos visando à interação universidade e escola.

Para o bom funcionamento das oficinas, houve preparação prévia com base em manual de orientações aos condutores e aos alunos. Esse manual foi apresentado e entregue aos bolsistas atuantes na pesquisa em sessão de treinamento realizada previamente às oficinas de aplicação das atividades com os alunos do $9^{\circ}$ ano, de modo a proporcionar o conhecimento dos materiais elaborados e a orientação dos professores e alunos IC Júnior para o uso adequado. Essa sessão de treinamento foi conduzida pela equipe de desenvolvimento da pesquisa na Universidade, formada pelo professor coordenador do projeto, pelos acadêmicos IC, pelo aluno de doutorado e pelo estagiário da Computação.

Desse modo, foi constituída uma equipe que podia conduzir o trabalho de forma produtiva: as atividades eram apresentadas, os alunos as respondiam (uso) e justificavam (consciência) suas respostas, que eram discutidas coletivamente e reformuladas quando necessário. Para a realização das atividades, os alunos eram orientados a resolver as questões de uso da estratégia e, logo após, justificar a escolha de suas respostas, explicando como haviam pensado para chegar a elas.

Participaram da pesquisa 59 alunos de $9^{\circ}$ ano do EF da escola selecionada, correspondentes a dois grupos (turmas inteiras): uma, com 37 alunos, designada para trabalho com tecnologia virtual e uma, somando 22 alunos, designada para trabalho com tecnologia não virtual. A indicação das turmas para o desenvolvimento do trabalho com as respectivas tecnologias foram tomadas em conjunto com as professoras desses alunos e os bolsistas do projeto, considerando a proposta pedagógica e as características de cada turma.

A investigação das contribuições das oficinas foi realizada com base em Pré e Póstestes de Uso da Estratégia de Leitura de Predição e Consciência Linguística nesse Uso, preenchidos pelos alunos antes e após as oficinas. Esses dois testes constituem instrumentos de pesquisa $a d$ hoc elaborados para o contexto de pesquisa em investigação 
pela equipe de professores e bolsistas da Universidade, tendo sido proposto em uma das etapas de desenvolvimento do projeto de pesquisa. Foram organizados com apoio nos textos da mesma natureza dos trabalhados nas oficinas, sendo constituídos de tarefas de uso das estratégias de leitura e, a seguir, da explicação do processo utilizado para realização das tarefas, mantendo, assim, as características estruturais das atividades. Desse modo, em cada teste foi utilizado um texto com uma questão. A tarefa apresenta característica semelhante às tarefas propostas nas atividades virtuais e não virtuais construídas. Constituído de um texto (conto) cujo final foi retirado propositalmente, o teste tem uma questão de múltipla escolha para verificar o uso da estratégia de predição (UELP) e uma questão de justificativa da escolha da alternativa (CUELP) para verificar a consciência do aluno sobre o uso dessa estratégia. Constituem textos selecionados: "O Encontro", de Leon Eliachar, para o Pré-teste de Uso da Estratégia de Leitura de Predição e Consciência Linguística nesse Uso; e "De Cabeça Pensada", de Marina Colasanti, para o Pós-teste de Uso da Estratégia de Leitura de Predição e Consciência Linguística nesse Uso. No que se refere à aplicação, foi realizada pela doutoranda com auxílio dos bolsistas IC da universidade.

Os dados obtidos foram levantados, tabulados e organizados em tabelas. Posteriormente, foram calculados com o apoio de um estatístico ${ }^{5}$, que orientou a equipe para uso de dois testes, considerando as variáveis uso e consciência no uso da estratégia de predição: o McNemar Test, para o UELP, e o Wilcoxon Test, para o CUELP. Essas análises possibilitaram a obtenção dos resultados apresentados a seguir.

\section{RESULTADOS}

Os resultados decorrem dos dados obtidos na aplicação do pré e do pós-teste do UELP e do CUELP, realizados antes e depois das oficinas com as atividades construídas em tecnologia virtual e tecnologia não virtual. Os dados foram tratados estatisticamente, para verificação da mudança de comportamento no pré-teste e no pós-teste no UELP e no CUELP.

As Tabelas 1 e 2 apresentam informações sobre o UELP, referentes ao pré-teste e ao pós-teste - escores, percentuais e valores de significância.

Tabela 1 - UELP: Escores e percentuais de erros e acertos no pré-teste e pós-teste

\begin{tabular}{lrrrr}
\hline & \multicolumn{2}{c}{ Pré-teste } & \multicolumn{2}{c}{ Pós-teste } \\
\cline { 2 - 5 } & Escore & Percentual & Escore & Percentual \\
\hline Erro & 41 & 69,5 & 4 & 6,8 \\
Acerto & 18 & 30,5 & 55 & 93,2 \\
\hline $\mathrm{N}$ & 59 & 100,0 & 59 & 100,0 \\
\hline
\end{tabular}

\footnotetext{
${ }^{5}$ Prof. Dr. João Feliz - Faculdade de Matemática da PUCRS. 
Conforme a Tabela 1, os cálculos, feitos com base no N 59, mostram que, no préteste, houve 18 acertos e 41 erros, isto é, 30,5\% de acertos e 69,5\% de erros, evidenciando que os sujeitos tinham condições pouco favoráveis de ingresso. No pós-teste, os dados indicam uma situação inversa, pois os acertos $(55 / 93,2 \%)$ ultrapassaram os erros (4 / $6,8 \%)$.

A Tabela 2 disponibiliza o desempenho dos sujeitos no pré e pós-teste e o valor de significância dessa comparação.

Tabela 2 - UELP: escores e valor de significância pré e pós-teste

\begin{tabular}{llll}
\hline Pré & Pós & & \\
& Erro & Acerto & \\
Erro & 2 & 39 & \\
Acerto & 2 & 16 & \\
& & & Test Statistics Pré\&Pós \\
\hline $\mathrm{N}$ & - & - & 59 \\
Chi-Square & - & - & 31,610 \\
Asymp. Sig. & - & - &, 000 \\
\hline
\end{tabular}

Considerando os 59 sujeitos, 39 cometeram erro no pré-teste e inverteram esse resultado no pós-teste e 16 mantiveram, no pós-teste, o bom desempenho registrado no pré-teste. $\mathrm{O}$ valor de significância decorrente dessa comparação é significativo, sendo o valor de $p$ inferior a $0,005(p<0,005)$. Os dados das Tabelas 1 e 2 , considerando a diferença significativa entre o pré-teste e o pós-teste, indicam que as oficinas e seus materiais contribuíram para a evolução dos sujeitos no UELP na leitura de contos.

As Tabelas 3 e 4 apresentam informações sobre o UELP referentes ao pré-teste e ao pós-teste por ambiente - virtual e não virtual - escores, percentuais e valores de significância.

Os resultados da Tabela 3 revelam o comportamento dos dados no pré e pós-teste quanto à tecnologia virtual e o valor de significância resultante dessa relação.

Tabela 3 - UELP em tecnologia virtual:

escores e valor de significância da comparação pré e pós-teste

\begin{tabular}{llll}
\hline Pré & Pós & \\
& Erro & Acerto & \\
Erro & 2 & 21 & \\
Acerto & 1 & 13 & \\
& & & Test Statistics Pré\&Pós \\
$\mathrm{N}$ & - & - & 37 \\
Exact Sig. & - & - &, 000 \\
\hline
\end{tabular}

Conforme os dados da Tabela 3, é possível verificar que 21 alunos apresentaram crescimento ao errarem no pré-teste e acertarem no pós-teste e que 13 alunos acertaram no pré e mantiveram o bom desempenho no pós. O valor de significância resultante dessa comparação evidencia $p$ inferior a 0,005 , corroborando a diferença estatisticamente 
significativa na comparação pré e pós-teste. Esse resultado revela que os materiais construídos em tecnologia virtual também contribuíram para a evolução do desempenho dos alunos no UELP na leitura do conto.

Os dados da Tabela 4 correspondem ao desempenho dos alunos no pré e pós-teste do UELP em tecnologia não virtual. A Tabela também disponibiliza o valor de significância decorrente da comparação pré e pós-teste, com $\mathrm{N}$ igual a 22.

Tabela 4 - UELP em tecnologia não virtual: escores e valor de significância da comparação pré e pós-teste

\begin{tabular}{llll}
\hline Pré & Pós & \\
\hline \multirow{4}{*}{ Erro } & Erro & Acerto \\
Acerto & 0 & 18 & \\
& 1 & 3 & Test Statistics Pré\&Pós \\
\hline $\mathrm{N}$ & & & 22 \\
Exact Sig. & - & - &, 000 \\
\hline
\end{tabular}

A análise da Tabela 4 revela que, dos 22 sujeitos que realizaram as atividades em ambiente não virtual, 18 apresentaram evolução de desempenho e 3 mantiveram o bom resultado registrado no pré-teste. O valor de significância decorrente dessa comparação é inferior a 0,005 , sendo, portanto, estatisticamente significativo. Esse dado indica que as atividades proporcionadas em ambiente não virtual também contribuíram para o aprimoramento dos alunos no UELP na leitura do conto.

A Tabela 5 apresenta os dados comparativos entre os ambientes de aprendizado virtual e não virtual - no pós-teste e o valor de significância resultante dessa comparação.

Tabela 5 - UELP por tecnologia: percentuais de erros e acertos e valor de significância da comparação virtual/não virtual no pós-teste

\begin{tabular}{|c|c|c|c|c|c|c|}
\hline & \multicolumn{6}{|c|}{ Ambiente } \\
\hline & & & Virtual & Não Virtual & Total & Chi-Square Test \\
\hline & \multirow[t]{3}{*}{0} & Count & 3 & 1 & 4 & - \\
\hline & & $\%$ within pós & $75,0 \%$ & $25,0 \%$ & $100,0 \%$ & - \\
\hline & & $\%$ within Ambiente & $8,1 \%$ & $4,5 \%$ & $6,8 \%$ & - \\
\hline \multirow[t]{7}{*}{ Pós-teste } & & Count & 34 & 21 & 55 & - \\
\hline & & $\%$ within pós & $61,8 \%$ & $38,2 \%$ & $100,0 \%$ & - \\
\hline & & $\%$ within Ambiente & $91,9 \%$ & $95,5 \%$ & $93,2 \%$ & - \\
\hline & Total & Count & 37 & 22 & 59 & - \\
\hline & & $\%$ within pós & $62,7 \%$ & $37,3 \%$ & $100,0 \%$ & - \\
\hline & & $\%$ within Ambiente & $100,0 \%$ & $100,0 \%$ & $100,0 \%$ & - \\
\hline & $\begin{array}{l}\text { Fisher's Exact - } \\
\text { Test }\end{array}$ & & - & - & - & 1,000 \\
\hline
\end{tabular}


$\mathrm{Na}$ Tabela 5, 0 equivale ao erro e 1 ao acerto. Analisando os dados correspondentes à linha dos acertos (1), dos 55 obtidos no total, $34(61,8 \%)$ equivalem ao ambiente virtual e $21(38,2 \%)$ ao não virtual. Esse resultado indica uma tendência favorável ao ambiente virtual, uma vez que representa o percentual mais alto de acertos, considerando a soma do total de acertos obtidos nos dois ambientes. Os cálculos estatísticos, no entanto, revelam valor de $p$ superior a 0,005 $(p=1,000)$, o que indica ausência de diferença significativa entre os dois ambientes de aprendizado.

Os dados disponibilizados nas tabelas que seguem correspondem aos resultados da CUELP do conto. O teste estatístico selecionado para tratamento dos dados da CUELP foi o Teste de Wilcoxon Signed Ranks Test cujo cálculo faz o ranqueamento dos escores, colocando-os em postos (ranks). Também nesse procedimento estatístico, a presença de significância nos resultados decorre de valor de $p$ inferior a 0,005 $(p<0,005)$.

A Tabela 6 apresenta informações globais sobre a CUELP, referentes ao pré-teste e ao pós-teste - escores, percentuais e valores de significância - com N 59.

\section{Tabela 6 - CUELP: médias de rankings e}

valor de significância da comparação pré e pós-teste

\begin{tabular}{llllll}
\hline & & $\mathrm{N}$ & \multicolumn{3}{l}{ Mean Rank Sum of Ranks Test Statistics } \\
\cline { 2 - 5 } Pés - Pré & Negative Ranks & 3 & 19,50 & 58,50 & - \\
& Positive Ranks & 52 & 28,49 & 1481,50 & - \\
& Ties & 4 & - & - & - \\
& Total & 59 & - & - & - \\
& Z & - & - & - & $-5,991$ \\
& Asymp. Sig. & - & - & - &, 000 \\
\hline
\end{tabular}

Os cálculos da tabela 6 têm como base o N 59 e revelam as médias dos escores em postos. Desse modo, considerando o total de 59 sujeitos, 52 alcançaram ranking de escores positivo, o que corresponde a um percentual de $28,49 \%$ na comparação pré e pósteste. $\mathrm{O}$ cálculo estatístico também mostra que, nessa relação pré e pós-teste, a diferença é fortemente significativa, sendo o valor de $p$ inferior a $0,005(p=, 000)$.

As Tabelas 7, 8 e 9 apresentam informações sobre a CUELP, referentes ao pré-teste e ao pós-teste por ambiente e na comparação entre os ambientes - escores, percentuais e valores de significância.

No uso da tecnologia virtual, o desempenho também é produtivo, considerando que, dos 37 sujeitos ( $\mathrm{N}$ do ambiente virtual), 32 alunos $(17,88)$ apresentaram ranking positivo na comparação pré e pós-teste. $\mathrm{O}$ valor de significância dessa comparação (pré e pósteste) é fortemente significativo, sendo $p$ inferior a $0,005(p<0,005)$. Esse resultado evidencia os benefícios das oficinas realizadas e dos materiais virtuais construídos para o aprimoramento da CUELP dos alunos na leitura do conto.

A Tabela 8 mostra os resultados da CUELP na tecnologia não virtual, sendo 22 o N. 
Tabela 7 - CUELP em tecnologia virtual:

médias de rankings e valor de significância da comparação pré e pós-teste

\begin{tabular}{llllll}
\hline & N & \multicolumn{3}{l}{ Mean Rank Sum of Ranks Test Statistics } \\
\hline \multirow{4}{*}{ Pós - Pré } & Negative Ranks & 2 & 11,50 & 23,00 & - \\
& Positive Ranks & 32 & 17,88 & 572,00 & - \\
& Ties & 3 & - & - & - \\
& Total & 37 & - & - & - \\
& Z & - & - & - & $-4,721$ \\
& Asymp. Sig. & - & - & - &, 000 \\
\hline
\end{tabular}

Tabela 8 - CUELP em tecnologia não virtual:

médias de rankings e valor de significância da comparação pré e pós-teste

\begin{tabular}{llllll}
\hline & $\mathrm{N}$ & \multicolumn{3}{l}{ Mean Rank Sum of Ranks Test Statistics } \\
\hline \multirow{4}{*}{ Pós - Pré } & Negative Ranks & 1 & 8,50 & 8,50 & - \\
& Positive Ranks & 20 & 11,13 & 222,50 & - \\
& Ties & 1 & - & - & - \\
& Total & 22 & - & - & - \\
& Z & - & - & - & $-3,736$ \\
& Asymp. Sig. & - & - & - &, 000 \\
\hline
\end{tabular}

Os dados da Tabela 8 revelam que, dos 22 sujeitos - total correspondente ao uso da tecnologia virtual -, 20 alunos $(11,13)$ registraram ranking positivo. Observando o valor de significância da comparação pré e pós-teste, os cálculos evidenciam valor de $p$ inferior a $0,005(p=, 000)$, indicando a presença de diferença significativa no desempenho dos alunos após a realização das oficinas com uso de materiais não virtuais.

A Tabela 9 disponibiliza as médias de ranking em cada tecnologia utilizada, bem como o cálculo decorrente da comparação entre os dois ambientes de aprendizado.

\section{Tabela 9 - CUELP por tecnologia:}

médias de rankings no pós-teste e valor de significância da comparação virtual/não virtual

\begin{tabular}{llllll}
\hline & & N & \multicolumn{3}{l}{ Mean Rank Sum of Ranks Test Statistics } \\
\hline \multirow{4}{*}{ Virtual } & 37 & 30,84 & 1141,00 & - \\
Pós & 22 & 28,59 & 629,00 & - \\
& Não virtual & 59 & - & - & - \\
& Total & - & - & - & 376,000 \\
& Mann-Whitney U & - & - & - & 629,000 \\
Wilcoxon W & - & - & - &,- 505 \\
Z & - & - & - &, 614 \\
& Asymp. Sig. & & & &
\end{tabular}


A análise dos dados da Tabela 9 revela tendência pequena, porém favorável ao ambiente virtual cuja média de ranking é 30,84 em relação à média de ranking do ambiente não virtual -28,59. Os resultados do cálculo estatístico evidenciam, porém, que essa diferença não é significativa, sendo o valor de $p$ superior a ,005 $(p=, 614)$.

Os resultados alcançados e até aqui expostos permitem responder às questões de pesquisa e propor encaminhamentos para a pesquisa e o ensino, tópicos desenvolvidos na próxima seção deste artigo.

\section{CONSIDERAÇÕES FINAIS}

Os resultados apresentados na seção anterior dão condições para responder às questões de pesquisa inicialmente estabelecidas neste artigo.

Considerando a questão 1 (Qual a diferença pré e pós-teste de oficinas com materiais virtuais e não virtuais com foco na estratégia de leitura de predição, em contos, para o uso dessa estratégia e a consciência linguística nesse uso ?), o tratamento estatístico indicou que a diferença de desempenho entre o pré-teste e o pós-teste é sempre significativa, no que tange ao tópico de investigação (uso e consciência linguística no uso) tanto considerando o $\mathrm{N}$ global quanto o $\mathrm{N}$ de cada tipo de tecnologia. Os resultados obtidos revelaram desempenhos superiores dos alunos do $9^{\circ}$ ano no UELP e na CUELP, após a realização das oficinas com uso dos materiais virtuais e não virtuais de leitura do conto. Considerando as condições pouco favoráveis dos alunos no pré-teste e o crescimento obtido no pós-teste, é possível afirmar que o material pedagógico construído para o desenvolvimento da compreensão leitora com uso de tecnologia virtual e não virtual contribuiu para o aprimoramento do conhecimento dos alunos no que se refere ao uso e à consciência no uso da estratégia de predição na leitura do conto.

Em relação à questão de pesquisa 2 (Em que medida o uso e a consciência linguística no uso da estratégia de leitura de predição trabalhada estão associados às tecnologias utilizadas - virtual e não virtual?), a análise estatística dos dados do UELP e da CUELP sob a perspectiva de cada tecnologia utilizada indicou que não há diferença significativa entre os ambientes utilizados para o ensino, seja no uso ou na consciência do uso. Os resultados revelaram evolução de desempenho na comparação pré e pós-teste em todas as condições investigadas, mas, no que se refere à comparação entre as tecnologias, os resultados não evidenciaram predomínio de uma tecnologia em detrimento da outra. Observando os dados em percentuais, é possível constatar uma tendência favorável pequena ao uso da tecnologia virtual, tanto no UELP quanto na CUELP, não sendo estatisticamente significativa.

Os resultados alcançados permitem fazer algumas reflexões sobre o contexto do ensino evidenciado por meio da realização da pesquisa. No que se refere ao crescimento obtido no pós-teste em relação ao pré-teste, esse comportamento produtivo pode ser decorrente de dois aspectos peculiares da metodologia de ensino construída para o desenvolvimento das oficinas: o direcionamento das atividades de compreensão para o aprimoramento da estratégia de predição leitora e o trabalho com o uso e com a consciência no uso dessa estratégia de leitura. Esses dois aspectos caracterizam os 
materiais elaborados como inovadores na medida em que os materiais de leitura usuais pouco abordam as estratégias de leitura e tampouco apresentam questões que proporcionem o seu uso e o desenvolvimento da consciência linguística sobre o seu uso. É possível, assim, atribuir às características dos materiais construídos a evolução significativa dos alunos do $9^{\circ}$ ano no pós-teste.

No que tange ao uso das tecnologias, a ausência de diferença significativa na comparação entre a tecnologia virtual e a tecnologia não virtual pode estar relacionada à experiência dos alunos em sala de aula com as duas tecnologias investigadas. Os alunos vivenciam atualmente uma dupla situação nas escolas em relação ao uso das tecnologias. Por um lado, eles apresentam interesse, domínio e facilidade no uso da tecnologia virtual, do que decorre a expectativa de apresentação de melhores desempenhos nesse ambiente. Por outro lado, o ambiente não virtual é predominante na escola e marca a trajetória histórica das práticas escolares às quais os alunos são submetidos diariamente. Nessa perspectiva, a ausência de diferença significativa entre as tecnologias pode ser resultado dessa dupla experiência vivenciada pelos alunos no contexto escolar.

Os resultados alcançados nessa pesquisa contribuem para o conhecimento das atuais condições de leitura dos alunos do $9^{\circ}$ ano do EF. São importantes também para o processo de construção de materiais de ensino que efetivamente favoreçam o aprendizado dos alunos, na medida em que evidenciam as dificuldades manifestadas pelos estudantes no pré-teste. Na busca por caminhos produtivos, a pesquisa mostrou a relevância de materiais construídos com foco no desenvolvimento do uso e da consciência no uso da estratégia de predição na leitura de contos. Os dados obtidos apontaram a importância, para a elaboração de atividades de compreensão leitora, da seleção e da organização de conteúdos fundamentados no uso da estratégia de leitura de predição e na consciência sobre seu uso, com base em contos com características diferenciadas, sendo, para isso, a Psicolinguística, um caminho teórico importante, na medida em que examina a compreensão e seus processos.

O estudo relatado indicou também a relevância da realização de pesquisas na direção da geração e aplicação de materiais pedagógicos para o desenvolvimento da compreensão leitora. A presente pesquisa investigou o uso e a consciência no uso da estratégia de predição na leitura de contos, cabendo salientar a necessidade e a importância de desenvolver outras pesquisas que examinem a predição na leitura de outros gêneros textuais, bem como outras estratégias de leitura em outros gêneros textuais e em outros anos escolares. Esses estudos são importantes, devendo ser estimulados porque, quando publicados, seus dados constituem informações norteadoras para o trabalho escolar, contribuindo para a identificação e os encaminhamentos necessários para a solução dos problemas no aprendizado dos alunos do EF.

Quanto ao uso de tecnologias, embora os resultados tenham sido estatisticamente não significativos, convém direcionar o olhar para a pequena vantagem obtida e incluir materiais virtuais e não virtuais no ensino, preferencialmente em situação complementar, dadas as semelhanças e diferenças entre os dois caminhos. Há que ter presentes também as definições teóricas a esse respeito apresentadas, que apontam suas contribuições para formação dos alunos como leitores, assim como as disposições desses jovens. 
Do ponto de vista teórico, o estudo, como já especificado, tem base psicolinguística, Desse modo, esteve voltado para a leitura como processo cognitivo, situando-se o conto como o material de leitura, escolha decorrente de sua presença na faixa escolar examinada. Está aí uma contribuição do trabalho desenvolvido - a abordagem de um determinado texto literário, o conto, como leitura em processo, mais especificamente no uso da estratégia de predição leitora e na consciência linguística sobre seu uso, neste caso.

Finalizando estas reflexões, ainda teoricamente, os resultados sobre a relação entre uso da estratégia leitora e a consciência sobre esse uso evidenciam que esses dois tópicos avançam no aprendizado, a partir de uma mesma situação de ensino, mas que isso ocorre com particularidades próprias. Isso significa que, embora haja essa progressão, não é prudente afirmar a existência de relações de determinação, sendo necessária a realização de outros estudos com esse objetivo especificamente.

\section{REFERÊNCIAS}

ADAM, J. M. A Linguística: introdução à análise textual dos discursos. São Paulo: Cortez, 2008.

AMODEO, M. T.; PEREIRA, V. W. O guessing game na leitura do conto literário. Linguarum Arena. Porto: UP, v.7. p. 49-64, 2016. Disponível em: <http://ler.letras.up.pt/uploads/ficheiros/14828.pdf.> Acesso em: 3 fev. 2017.

BAARS, B. J. A cognitive theory of consciousness. Cambridge: Cambridge Univ., 1993.

BÄCHLER, R. Conciencia y lenguaje: análisis del vínculo proyectado a través de la intencionalidad. Rev $G U$, v. 2, n. 4, p. 432-438, 2006.

BAZERMAN, C. (Autor); DIONÍSIO, A. P.; HOFFNAGEL, J. C. (Org.). Gêneros textuais, tipificação e interação. São Paulo: Cortez, 2009.

CHAROLLES, M. Introduction aux problèmes de la cohérence des textes. Langue Française, v. 38, n. 1, p. 7- 41, mai 1978.

COSCARELLI, C. V. Novas tecnologias, novos textos, novas formas de pensar. Belo Horizonte: Autêntica, 2002.

DEHAENE, S. The cognitive neuroscience of consciousness. Cambridge, Massachusetts: The MIT Press, 2001.

DEHAENE, S. Les neurones de la lecture. Paris: Odile Jacob, 2007.

DEHAENE, S. Signatures of consciousness - a talk by Stanislas Dehaene. Edge in Paris. Entrevista concedida a Edge Foundation, Inc., 2009. Disponível em:

<http://www.edge.org/3rd_culture/dehaene09/dehaene09_index.html>. Acesso em: 15 jul. 2010.

GOMBERT, J. É. Metalinguistic development. Chicago: The University of Chicago Press, 1992.

GOODMAN, K. S. Reading: A psycholinguistic guessing game. Journal of the Reading Specialist, v. 6, Issue 4, p. 126-135, 1967.

GOODMAN, K. S. Unidade na leitura - um modelo psicolinguístico transacional. Letras de Hoje, v. 26, n. 4, p. 9-43, dez. 1991 .

HALLIDAY, M. A. K.; HASAN, R. Cohesion in English. London: Longman, 1976.

KATO, M. A. O aprendizado da leitura. São Paulo: Martins Fontes, 1987.

KLEIMAN, A. Texto e leitor: aspectos cognitivos da leitura. Campinas: Pontes, 1989.

LEFFA, V. Aspectos da leitura: uma perspectiva psicolinguística. Porto Alegre: Sagra, 1996

MILLER, C. R. Estudos sobre gênero textual, agência e tecnologia. Recife: EUUFPE, 2009.

MOTA, M. Desenvolvimento metalinguístico: questões contemporâneas. São Paulo: Casa do Psicólogo, 2009. 
PEREIRA, I. Reading to learn on screens: challenges for research. In: PEREIRA, I. et al. (Org.). The Digital Literacy and Multimodal Practices of Young Children: Engaging with Emergent Research. Portugal: Institute of Education, University of Minho, 2016. p. 225-237.

PEREIRA, V. W. Computer-Based Learning of Reading and Writing in Elementary School. In: CESTARI, M. L.; MAAGERO, E.; TONNESSEN, E. S. (Orgs.). Networking Cultures. V. 1. Kristiansand: Portal Books, 2006. p. 107-117.

Compreensão leitora de alunos do Ensino Médio. Revista Virtual de Estudos da Linguagem, v. 6, n. 11, p. 1-15, ago. 2008. Disponível em:

<http://www.revel.inf.br/files/artigos/revel_11_compreensao_leitora_de_alunos_do_ensino_medio.pdf >. Acesso em: 03 fev. 2017.

Estratégias de leitura virtuais e não virtuais no ensino fundamental. In: CONGRESSO DA ABRALIN, 6., João Pessoa, PB, 2009. Anais do... João Pessoa: UFPA, 2009. p. 10-22.

Aprendizado da leitura e consciência linguística. In: ENCONTRO DO CELSUL, 9., Palhoça, SC, 2010. Anais do... Palhoça: Universidade do Sul de Santa Catarina, 2010. p. 1-11.

PEREIRA, V. W.; ANTUNES, C. Novas linguagens em leitura. In: BORTOLINI, A.; SOUZA, V. (Org.). Mediação tecnológica: construindo e inovando. Porto Alegre: EDIPUCRS, 2003. p. 419-440.

PEREIRA, V. W.; PICCINI, M. Preditibilidade: um estudo fundado pela Psicolingüística e pela Informática. Letras de Hoje, v. 41, n. 2, p. 305-324, jun. 2006.

RIGATTI, A. P.; PEREIRA, V. W. A consciência sintática no ensino da leitura e da escrita. In: NASCOLD, A. et al. (Org.). Aprendizado da leitura e da escrita: a ciência em interfaces. Natal: EDUFRN, 2015.

SCLIAR-CABRAL, L. Processamento bottom-up na leitura. Veredas Revista de Estudos Linguísticos, v. 12, n. 2, p. 24-33, 2/2008. Disponível em: <http://www.ufjf.br/revistaveredas/files/2009/12/artigo02.pdf.>. Acesso em: 22 maio 2011.

Processamento da leitura: recentes avanços das neurociências. In: PEREIRA, V. W.; COSTA, J. C. (Org.). Linguagem e cognição: relações interdisciplinares. Porto Alegre: EDIPUCRS, 2009, p. 49-60. SMITH, F. Compreendendo a leitura. Porto Alegre: Artes Médicas, 2003.

SPINILlO, A. G.; MOTA, M. M. P. E.; CORREA, J. Consciência metalinguística e compreensão da leitura: diferentes facetas de uma relação complexa. Educar em Revista, v. 38, n.1, p. 157-171, set./dez. 2010.

TONNESSEN, E. Reading the screen. In: CESTARI, M. L.; MAAGERO, E.; TONNESSEN, E. S. (Org.). Networking Cultures. v. 01. Kristiansand: Portal Books, 2006. p. 87-106.

Recebido em: 13/02/17. Aprovado em: 28/06/17.

Title: Prediction reading strategy at school: use and linguistic awareness in its use Authors: Vera Wannmacher Pereira; Thais Vargas dos Santos

Abstract: In this article, we report a study that examined the contribution, for students of the 9 th grade of Elementary School, of virtual and non-virtual materials with focus on the use of the prediction reading strategy and on the linguistic awareness of its use, using short story as text. Theoretically based on Psycholinguistics, especially regarding to these two central topics, it also used technologies as support. It involved production of materials and its application on workshops at the school chosen, elaboration and applications of tests before and after the workshops, as well as the continuous preparation of the scholarships teachers and students. The results indicated significant difference in the pre and post-test relationship on the use of the prediction strategy and on the awareness about its use; and on the comparison between the technologies, a favorable advantage to virtual one, although without statistically significant difference. As a conclusion, we can affirm that the research objective was achieved, recommending teaching in school with materials including the properties studied.

Keywords: Reading prediction. Use and linguistic awareness. Technology. Literary short story.

PEREIRA, Vera Wannmacher; SANTOS, Thais Vargas dos. Estratégia de leitura de predição na escola: uso e consciência linguística no seu uso. Linguagem em (Dis)curso - LemD, Tubarão, SC, v. 17, n. 3, p. 361-380, set./dez. 2017. 
Título: Estrategia de predicción lectora en la escuela: uso y conciencia lingüística en su uso Autores: Vera Wannmacher Pereira; Thais Vargas dos Santos

Resumen: En este artículo, se relata un estudio que examinó la contribución, para alumnos del $9^{\circ}$ año de la Enseñanza Primaria, de materiales virtuales y no virtuales con enfoque en el uso de la estrategia de predicción lectora y en la conciencia lingüística de su uso, utilizando el cuento como género textual. Tuvo como soporte teórico la Psicolingüística, especialmente en relación con estos dos temas centrales, y utilizó el apoyo de tecnologías. Envolvió producción de los materiales y su aplicación en talleres en la escuela elegida, elaboración y aplicación de instrumentos antes (pre prueba) y después (post prueba) de los talleres, así como preparación continuada de los alumnos becarios y profesores. Los resultados indicaron diferencia significativa en la relación entre pre y postprueba en el uso de la predicción y en la conciencia sobre su uso; y, en la comparación entre las tecnologías, ventaja favorable a la virtual, aunque sin diferencia estadística significativa. Como conclusión, cabe afirmar el logro del objetivo y recomendar el trabajo en la escuela con materiales con las propiedades estudiadas.

Palabras-clave: Predicción lectora. Uso y conciencia linguística. Tecnología. Cuento literario.

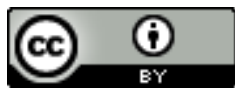

Este texto está licenciado com uma Licença Creative Commons Atribuição 4.0 Internacional.

PEREIRA, Vera Wannmacher; SANTOS, Thais Vargas dos. Estratégia de leitura de predição na escola: uso e consciência linguística no seu uso. Linguagem em (Dis)curso - LemD, Tubarão, SC, v. 17, n. 3, p. 361-380, set./dez. 2017. 